\title{
REVIEW
}

\section{Pharmacological therapies for acute respiratory distress syndrome}

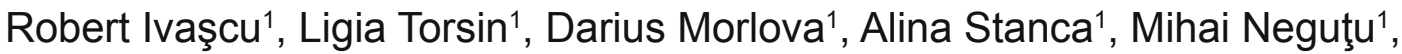 \\ Silvius Negoiţă ${ }^{1,2}$, Mădălina Duţu ${ }^{1,2}$ \\ ${ }^{1}$ Anaesthesiology and Critical Care Department, Elias Clinical Emergency Hospital, Bucharest, Romania \\ 2 Faculty of Medicine, "Carol Davila" University of Medicine and Pharmacy, Bucharest, Romania
}

\section{Correspondence to:}

Madalina Dutu, MD, PhD, Assist Prof

Faculty of Medicine, "Carol Davila" University of Medicine and Pharmacy, Bucarest, Romania.

E-mail: madalinadutu236@yahoo.com

\section{Conflicts of interests}

Nothing to declare

\section{Acknowledgment}

None

Funding: This research did not receive any specific grant from funding agencies in the public, commercial or not-for profit sectors.

Keywords: atrial fibrillation; quality of life; comorbidities; anticoagulants; mortality.

These authors take responsibility for all aspects of the reliability and freedom from bias of the data presented and their discussed interpretation.

Central Eur J Clin Res 2019;2(1):37-47

Received: 01.02.2019, Accepted: 01.03.2019, Published: 01.04.2019

Copyright $\odot 2018$ Central European Journal of Clinical Research. This is an open-access article distributed under the Creative Commons Attribution License, which permits unrestricted use, distribution, and reproduction in any medium, provided the original work is properly cited.

\section{Abstract}

Acute respiratory distress syndrome (ARDS) has no specific treatment, the only effective therapy currently being limited to minimizing potentially harmful ventilation and avoiding a positive fluid balance. These treatments could not be completely effective in severe disease and several measures must be undertaken simultaneously, including pharmacological therapies aimed at correcting the etiology or targeting the pathogenesis. In this review article we provide update on pharmacological thera- pies in ARDS, showing their effect on outcome in recent trials.

\section{Introduction}

Acute respiratory distress syndrome (ARDS) is a severe form of acute hypoxemic respiratory failure due to various direct or indirect lung insults [1]. Despite the heterogeneity of its causes, ARDS is characterized by a common final pathophysiologic pathway (non-cardiogenic pulmonary edema) and particular histopathology including diffuse alveolar damage, protein-rich alveolar edema, alveolar neutrophil influx, alveolar epithelium and capillary endo- 
thelium injury with subsequent cell death, hyaline membrane deposition and microthrombi formation, type II alveolar cells, fibroblasts and myofibroblasts proliferation [2,3].

Due to its complex etiology and variable definitions, the exact ARDS incidence varies from 64.2 to 78.9 per 100.000 person years in the US, $75 \%$ of cases displaying a moderate or severe form $[4,5]$. In addition, ARDS accounts for $10 \%$ of intensive care unit admissions worldwide [6]. However, its incidence has been constantly declining during the last 20 years, mainly due to adoption of preventive measures for reduction of the nosocomial ARDS incidence $[7,8,9]$. ARDS mortality is between 26 and $58 \%$, being influenced by disease severity (increases with hypoxemia severity) and etiology (lowest in trauma-induced ARDS, highest in sepsis related ARDS)[10]. Mortality remains still high even among ARDS survivors, many of them developing cognitive dysfunction, psychiatric illnesses or impaired physical and lung function, increasing the burden of the disease [11].

Despite its high incidence and severe outcomes, ARDS has no specific treatment, the only effective therapy currently being minimizing potentially harmful ventilation and avoiding a positive fluid balance. Thus, it becomes clear that the supportive measures designed for ARDS management are far from enough and a paradigm shift is fiercely needed. First, a better selection of patients at risk of ARDS and a bundle of measures adoption to prevent progression to ARDS is needed. Secondly, the discovery of an efficient therapy designed to reverse or modulate the characteristic proinflammatory and procoagulant response would certainly improve ARDS survival.

The focus of this article review is assessing the immunomodulatory pharmacotherapies employed for prevention or treatment of established ARDS and their effectiveness as stated in current literature.

\section{Prevention therapies for ARDS}

Considering the multi-hit theory of ARDS pathogenesis and the fact that patients develop rarely ARDS since their hospital admission, but rather later during their hospitalization, recent studies have concluded that ARDS might be preventable and there is a window of opportunity when prevention could be employed in high-risk groups $[9,12,13]$.

Several clinical scores have been developed in order to identify patients at high risk of ARDS. Currently, the best available tool, Lung Injury Prediction Score/LIPS evaluates multiple predisposing conditions and risk modifiers and a cutoff value $\geq 4$ has a sensitivity of 0.69 , specificity of 0.78 [12]. Even SpO2/FiO2 measured within $6 \mathrm{~h}$ since admission can be a powerful risk predictor, while combining serum levels of angiopoetin-2 with LIPS improves its prediction power $[14,15]$.

Apart from several supportive measures, bundled together in the Checklist for Lung Injury Prevention (CLIP), multiple systemic or inhalatory pharmacologic interventions targeting the pathophysiological pathways of ARDS are currently emerging [2,9].

\section{Systemic preventive therapy}

\section{Aspirin}

In preclinical studies it was shown that aspirin inhibits neutrophil-platelets interaction, decreases inflammation and edema, decreases intrapulmonary shunt and promotes resolution of inflammation through modulation of leukotriene and prostaglandins levels $[16,17,18,19]$. Although animal studies and several observational studies have returned positive results, the latest phase $2 b$ randomized clinical trial has reported no effect of preventive aspirin administration on ARDS incidence at one week [20,21]. Even if administration of aspirin for ARDS prevention was ineffective, there is an ongoing phase 2 RCT that aims to study the effect of low dose aspirin as a treatment for ARDS (ClincalTrials.gov ID: NCT02326350).

\section{Steroids}

As potent anti-inflammatory agents, systemic steroids have long been proposed in clinical trials as the ideal molecule in ARDS management. Up to now, four randomized trials using high-dose methylprednisolone in septic shock patients considered to be at high risk of ARDS proved no benefit of steroid treatment and even a higher incidence of ARDS and mortality [22, 23]. However, these findings results should not be considered a drawback because studies were designed in the '90s and since that time better scores for ARDS risk evaluation have emerged and thus the possibility for better conducted prevention trials has flourished [24].

\section{Statin}

Originally developed for the treatment of dyslipidemia, statins are shown to exhibit immunomodulatory effects [2,22]. Although preclinical studies have returned positive outcomes 
$[25,26]$, prospective observational human studies have revealed mixed results, some investigators proving that prehospital statin use might be protective against sepsis and acute lung injury [27], while others failing to prove any statistically significant benefit [29]. In addition, a recent 2016 meta-analysis has concluded that prior statin therapy does not lower the risk of developing ARDS [30].

\section{Angiotensin-converting enzyme (ACE)}

As pulmonary angiotensin-converting enzyme activity may play a role in ARDS pathogenesis, renin-angiotensin-aldosterone system (RAAS) blockers have sparked researchers' interest [31]. Although animal studies have reported a benefit of RAAS blockers in ARDS prevention [32,33], conflicting results have issued from human observational studies: while some suggested a protective effect of prehospital therapy with these agents [34], investigators analyzing the LIPS cohort proved that, apart from conferring no benefit, outpatient therapy with RAAS blockers may actually increase mortality in ALI patients [35].

\section{Vitamin D}

Vitamin $D$ is a modulator of immune responses with controversial antioxidant activity (36). Vitamin D deficiency was associated with an exaggerated alveolar inflammation, epithelial damage, hypoxia and a higher risk of acute respiratory failure in critically ill patients $[37,38]$. Lower levels of vitamin $D$ matched an increased prevalence of ARDS but without any influence on mortality [39].

\section{Carnosine}

Carnosine, a small dipeptide with antioxidant activity which shows promising results in suppressing pulmonary edema, tissue injury and inflammation in a murine model, while decreasing reactive oxygen species production in vivo, with potential benefits in suppressing the onset and progression of ARDS [40].

\section{Dilmapimod and bevacizumab}

Newly employed molecules for ARDS prevention are dilmapimod (SB-681323) and bevacizumab. SB-681323 is a selective inhibitor of p38 alpha mitogen-activated protein kinase, able to reduce lung injury due to pancreatitis and burns in preclinical studies. A phase 2a ran- domized clinical trial investigating its efficacy in preventing ARDS in trauma patients has proven increased tolerability and a reduced incidence of ARDS in the study cohort [41]. Bevacizumab, a recombinant humanized monoclonal antibody inhibiting vascular endothelial growth factor $A$, was also the subject of a phase 2 clinical trial for ARDS prevention, recently withdrawn due to a lack of funding [42].

\section{Inhaled preventive therapies}

\section{Corticosteroids}

Although results from previous studies using intravenous administration of corticosteroids were not promising, the advent of inhaled delivery steroids, bypassing the systemic side-effects of corticotherapy, has yielded positive results in attenuating lung injury in animal models [43].

\section{Combined corticosteroids and beta-agonists}

The anti-inflammatory effect of both beta-agonists and inhaled corticosteroids raised the hypothesis of using them in tandem. In a phase Ila trial the combined inhaled therapy increased oxygenation, lowered ARDS incidence and shortened hospital length of stay whilst proving to be the first safe and effective intervention in preventing/ameliorating ARDS [44].

\section{Heparin}

One mechanism in the physiopathology of ARDS is the fibrin accumulation/deposition via local inflammation and coagulation impairment. The anti-inflammatory effects of heparin are due to its binding to other "heparin binding proteins" such as complement proteins, interferons, fibroblast growth factor and other cytokines [45]. In smoke inhalation-associated ALI, inhaled anticoagulation regimens improve survival and decrease morbidity [46].

\section{Therapies for ARDS treatment}

\section{Neuromuscular blocking agents}

Until recently, a "less is more" strategy has been applied to neuromuscular blocking agents (NMBA) in ARDS. NBMA' use influences ARDS mortality through a mild anti-inflammatory effect, respiratory muscles oxygen consumption's decrease, arterial and mixed venous oxygenation's increase and ventilator-induced lung 
injury (VILI) prevention [47]. Cisatracurium, a nondepolarising NMBA has been shown to inhibit inflammatory responses and to regulate the immune functions in sepsis in a murine model by [48]. NBMA treatment is associated with decreased level of the epithelial and endothelial lung injury biomarkers and attenuate systemic inflammation in patients with severe ARDS [49]. In present, NMBA are part of the recommended pharmaceutical arsenal employed to treat acute ARDS.

\section{Macrolide antibiotics}

Animal models studies of ARDS suggest that macrolides possess immunomodulatory and anti-inflammatory effects. In vitro experiments macrolides reduce TNFa, IL1 $\beta$ and IL6 levels in a dose dependent-manner [50]. They also limit immune complex-induced lung injury in rats by inhibiting the inducible nitric oxide synthase gene expression and cytokine release [51]. Moreover, macrolides are used for their immunomodulatory effects in chronic lung diseases that include diffuse panbronchiolitis, cystic fibrosis, chronic obstructive pulmonary disease and asthma [52]. A low-dose and long-term macrolide treatment showed a reduction in IL1 $\beta$ and IL8 levels of the bronchoalveolar lavage fluid of patients with diffuse panbronchiolitis [53].

These non-bacterial effects of macrolide treatment may also be advantageous in the treatment of ARDS. Although to date there are no randomized clinical studies, several secondary analysis studies have associated the use of macrolides with beneficial effect and even decreased mortality. Walkey et al analyzed the data collected from an ARDS Network RCT - Lisofylline and Respiratory Management of Acute Lung Injury Trial. Use of erythromycin and azithromycin within the first 60 hours of ALI diagnosis, for a median period of 4 days was associated with lower 180-day mortality and shorter time to successful discontinuation of mechanical ventilation [54]. Similarly, Kawamura et all found that use of intravenous azithromycin starting within $24 \mathrm{~h}$ of ARDS diagnosis is associated with a lower mortality and a shorter time of mechanical ventilation [55]. Simonis et al found that low-dose erythromycin, prescribed for another reason than infections, was associated with reduced 30-day mortality in the group of patients with low inflammatory biomarkers levels or non-pulmonary type of ARDS [56].

\section{Granulocyte/macrophage colony-stimulating factor}

The resident alveolar macrophages' response to pathogen recognition consist of
TNFa release which induces epithelial granulocyte/macrophage colony-stimulating factor (GM-CSF) expression[57]. GM-CSF regulates surfactant homeostasis, modulates the immune functions of alveolar macrophages and dendritic cells and promotes epithelial repair processes in viral infections as well as bacterial pneumonia[58,59]. Moreover, patients who survive ARDS have higher concentrations of GM-CSF in their bronchoalveolar lavage fluids. In a RCT including 131 patients with ARDS, intravenous GM-CSF has been administered for 14 days, showing no improvement in ventilator-free days, 28-day mortality or organ failure[(60].

However, a report on six patients with pneumonia-associated ARDS who received inhalational GM-CSF revealed a significant improvement of oxygenation, an increase in lung compliance and a decrease in morbidity scores. Furthermore, a RCT that evaluates the efficacy and safety of inhaled GM-CSF in patients with pneumonia associated ARDS is ongoing (ClinicalTrials.gov ID: NCT02595060).

\section{Vitamin C}

Vitamin C administration in critical patients decreases the vasopressor therapy and mechanical ventilation duration, without affecting on 30-day mortality[61]. Data about its effect on ARDS patients are quite limited, with only a few case reports published in the literature (first in 2016), but with positive results [62,63,4]. There is currently an ongoing 2017 study that evaluates the impact of high dose of Vitamin C, 10 grams per day, on ARDS patients.

\section{Ineffective therapies}

Multiple physiological mechanisms are disturbed within the ARDS, and so many adjuvant therapies have been used over time in an attempt to restore the normal function of the morphological unit of the lung. Many of them have proved ineffective.

\section{Antioxidants}

Over the last 20 years, many studies have shown that oxidative stress has negative impact on the evolution of critical patients, and so it has been considered that antioxidant medication can improve the outcome of critical patients. In 2013, Jain M showed that the effect of antioxidants can be both positive and negative, depending greatly on time and dose administered[65].

\section{$N$ acetylcysteine}

$\mathrm{N}$ acetylcysteine is one of the most used antioxidants in intensive care units. $\mathrm{N}$-ace- 
tyl-cysteine (NAC) is a known compound that reduces oxidative stress by maintaining intracellular stores of reduced glutathione. NAC has been shown to exhibit prophylactic effects on the development of LPS-induced ALI in animal models, limiting TNFa production, as well as decreasing fibroproliferation in ventilation-induced lung injury[66,67]. Adhikari et al demonstrated that short-term mortality was not influenced by NAC administration in ARDS[68]. More, if non administered during the first 24 hours of ARDS, NAC produced myocardial depression[69]. In a meta-analysis from 2017, it was noted that the time spent in the ICU was reduced without influencing the 30-day mortality and gas exchange (PaO2 / FiO2) in patients receiving NAC[70].

\section{Glutamine}

Most literature data suggest that glutamine administration either has no benefit or it has a negative effect on the evolution of critical patients[71]. However, in 2016, an experimental study on rat or mice lungs with ARDS suggests that glutamine administration could be beneficial in ARDS[72].

\section{Vitamin E}

Vitamin $\mathrm{E}$ is an antioxidant incorporated in cell membranes with the role of protecting polyunsaturated fatty acids against peroxidation demonstrating a decrease in its concentration in patients with ARDS, along with increased plasma levels of lipoperoxides[73]. A study which included critically ill surgical patients revealed a decrease in the incidence of ARDS and pneumonia, as well as a decrease in the duration of hospitalization and mechanical ventilation, mortality rates and proinflammatory cytokine levels in the bronchoalveolar lavage fluid in the case of patients receiving prophylactic, enteral, vitamin $C$ and vitamin $E$ in the first 24 hours - either postoperatively or after trauma[74]. A similar study on critically ill patients demonstrated that the simultaneous enteral administration of vitamin $C$ and vitamin $E$ had no impact on the reduction in ARDS incidence, but had a positive impact on the duration of mechanical ventilation and all-cause mortality[75]. However, there are no studies evaluating the effectiveness of the administration of vitamin $E$ as a single agent in the prevention and/or treatment of ARDS.

\section{Beta-carotene}

Beta-Carotene is a membrane antioxidant with pro-oxidative properties at partial pressures of oxygen greater than $150 \mathrm{mmHg}$, with a decreased plasma concentration in ARDS[76].
Although the association of beta-carotene with other antioxidants and omega 3 or GLA fatty acids has been studied, without improving the outcome, the administration of beta-carotene as treatment has not been yet evaluated[77].

\section{Omega 3}

Omega 3 (n-3) fatty acids such as docosahexaenoic acid (DHA) and eicosapentaenoic acid (EPA) lead to the formation of eicosanoids that are less reactive and less inflammatory than the ones formed by omega $6(n-6)$ fatty acids. The $n-6$ gamma-linolenic acid (GLA) associated to omega 3 fatty acids reduces the production of leukotriene and increases the production of prostaglandin E1.[78]. There is an inverse correlation between the risk of developing ARDS and the levels of omega-3 and GLA fatty acids. Previous studies have demonstrated the relation between dietary supplementation with EPA and GLA and the reduction of lung inflammation, as well the improvement of clinical outcome[79]. Despite this evidence, a multicenter RCT published in 2011 has not shown any association between the dietary supplementation with EPA, GLA, DHA or antioxidants (vitamin C, vitamin E, beta carotene, zinc, selenium, taurine, L-carnitine) and the improvement of clinical outcome, pulmonary physiology, and systemic inflammatory markers. Moreover, this supplementation turned out to be potentially harmful by decreasing the number of ventilator-free and ICU-free days[77].

\section{Statins}

Since statins have an anti-inflammatory effect and interfere with endothelial modulation, they have been thought to have a positive effect on ARDS. Multiple literature studies have shown that statin use has had no impact on mortality, mechanical ventilation duration or ICU hospitalisation[80,81]. In 2018, Feng made a meta-analysis to show that although statin use does not have a direct effect on mortality and sepsis, it reduced the number of days of mechanical ventilation, the SOFA score[82].

\section{Surfanctant}

Surfactant's use in ARDS in children, raised the hypothesis of its effectiveness also in the ARDS in adult patient. A a meta-analysis including 1270 patients showed that the surfactant's use had no impact on mortality but produced an improvement in oxygenation[83]. In 2019, Shan-Shan and his team concluded after 11 studies involving 3038 patients that there was no improvement in mortality or oxygenation in patients treated with exogenous surfactant[84]. 


\section{Keratinocyte growth factor}

Keratinocyte growth factor (KGF) is specifically secreted by fibroblasts and is one of the factors contributing to the re-epithelization of alveolar cells, especially type II pneumocytes, thus reducing capillary permeability and alveolar edema. In a first study, keratinocyte growth factor administration has been shown to produce an alveolar medium that augments the healing of cellular lesions, which means that its use in ARDS may be beneficial[85]. But McAuley and his colleagues found that the mortality rate was higher in the KGF group than in the placebo group[86].

\section{Neutrophil elastase inhibitor (sivelestat)}

Neutrophil elastase is a serine protease that is capable of degrading elastin, collagen and pulmonary surfactant, as well as inducing pro-inflammatory cytokines. Sivelestat, a drug approved in Japan and South Korea, slows down the lung injury progression by inhibiting the pathophysiological pathways, as shown in several studies on animals. The decrease in plasma levels in neutrophil elastase activity linked to sivelestat administration was not associated to $\mathrm{PaO} 2$ / FiO2 ratio or SOFA score[87]. STRIVE multicenter study from 2004, a double-blind, placebo-controlled trial, demonstrated that the administration of sivelestat in patients diagnosed with acute lung injury does not improve the 28-day mortality rate or the number of ventilator-free days. Moreover, the all-cause mortality rate at 180 days was significantly higher among patients treated with sivelestat[88]. A further meta-analysis from 2010 of randomized controlled trials, revealed that sivelestat des not decrease mortality in critically ill patients with ARDS[89].

\section{Beta agonist}

Studies on animals have demonstrated the resolution of pulmonary edema by increasing sodium transport through the alveolar epithelium, mediated by beta 2 receptors[90]. Clinically, the administration of inhaled salmeterol led to a reduction in the incidence of high-altitude pulmonary edema]91]. Based on these findings, scientists started wondering whether beta 2 agonists could be used in the treatment of ARDS. The first randomized clinical trial, Albuterol to Treat Acute Lung Injury (ALTA), did not reveal any differences between patients treated with albuterol (salbutamol) and placebo in ventilator-free days number, mortality before hospital discharge, as well as occurrence of cardiac arrhythmias[92]. The second study, BALTI-2, studied efficiency of continuous intravenous administration of beta 2 agonists (salbutamol) in ARDS, but had to be discontinued due to an increase in the 28-day mortality rates in the salbutamol group[93].

\section{Prostaglandin E1}

Earlier studies, performed on a small number of patients, have demonstrated the beneficial effects of prostaglandin $E$ in reducing pulmonary and systemic vasoconstriction, increasing arterial oxygen tension, cardiac output, oxygen delivery and oxygen consumption, as well as increasing pulmonary compliance and decreasing ventilator dependence[94]. Subsequently, a randomized multicenter clinical trial compared the intravenous administration of liposomal prostaglandin $\mathrm{E}$ with placebo in patients with ARDS. The treatment based on prostaglandin $\mathrm{E}$ shortened the time of improvement of the $\mathrm{PaO} 2$ / FiO2 ratio, but did not, however, reduce mortality rates or the number of ventilator-free days[95]. PGE1 administration through inhalation improved oxygenation, lowered pulmonary artery pressure, caused arterial hypotension as a side effect, but a clinical benefit cannot be demonstrated[96].

\section{Nitric oxide}

Inhaled nitric oxide causes selective pulmonary vasodilation with improved matching of perfusion with ventilation, as well as decreased pulmonary artery pressure, without causing systemic vasodilation[97]. Despite the transient improvement in oxygenation, a Cochrane systematic review revealed that $\mathrm{NO}$ administered through inhalation did not have any benefit in terms of survival rates. Furthermore, inhaled NO was associated with a higher incidence of impairment of renal function[98].

\section{Recombinant human activated protein C (rhAPC)}

Starting from the close link between inflammation and clotting, it has been demonstrated that alveolar deposits of fibrin and vascular microthrombi perpetuate alveolar inflammation and alveolar capillary barrier dysfunction[99]. Furthermore, ARDS patients have been shown to exhibit a decrease in plasma levels of protein $\mathrm{C}$ and an increase in plasma levels of inhibin-1 
plasminogen activator - the magnitude of these quantitative changes correlates with mortality, ventilator support and organ dysfunction[100]. Despite this findings, a RCT concluded that administering rhAPC to patients with ARDS neither improved the pulmonary leak index, assessed by measuring the intravascular-alveolar transport ratio of the transferrin-bound isotope $67 \mathrm{Ga}$, nor did it bring clinical benefits[101].

\section{Conclusions}

Despite multiple pharmacological therapies investigated with encouraging experimental and early clinical results, to date there are few effective agents for prevention and treatment of ARDS. The heterogeneity of the therapeutic measures studied is linked to the heterogeneity of the ARDS syndrome that might require a more targeted or personalized management addressed to different biologic pathways activated in each type of ARDS illness. The principles of ARDS treatment should include a valuable method of identifying at-risk subjects and selecting those most likely to benefit from early interventions to prevent progression, diagnosis criteria and specific etiological treatment and finally, ARDS severity classification. All measures must be undertaken simultaneously in order to improve survival.

\section{References}

1. Allen GB, Parsons PE. Acute Respiratory Failure due to Acute Respiratory Distress Syndrome and Pulmonary Edema. In: Irwin RS, Lilly CM, Mayo PH, Rippe JM, editors. Irwin and Rippe's Intensive Care Medicine. 8th Editio. Philadelphia: Lippincott Williams \& Wilkins; 2018. p. 1454-67.

2. Ruthman CA, Festic E. Emerging Therapies for the Prevention of Acute Respiratory Distress Syndrome. Ther Adv Respir Dis. 2015;9(4):173-87.

3. Ware LB, Bastarache JA, Bernard GR. Acute Respiratory Distress Syndrome. In: Vincent J-L, Abraham E, Moore FA, Kochanek PM, Fink MP, editors. Textbook of Critical Care. 7th Editio. Philadelphia: Elsevier; 2017. p. 413-23.

4. Rubenfeld G, Caldwell E, Peabody E, Weaver J, Martin DP, Neff M, et al. Incidence and outcomes of acute lung injury. $\mathrm{N}$ Engl J Med. 2005;353:1685-93.

5. Goss C, Brower R, Hudson L, Rubenfeld G, Network A. Incidence of acute lung injury in the United States. Crit Care Med. 2003;31(6):1607-11.
6. Dries DJ. ARDS: From Syndrome to Disease. Prevention and Genomics. Air Med J. 2019;38:7-9.

7. Li G, Malinchoc M, Cartin-Ceba R, Venkata CV, Kor DJ, Peters SG, et al. Eight-year trend of acute respiratory distress syndrome: A population-based study in Olmsted County, Minnesota. Am J Respir Crit Care Med. 2011;183:59-66.

8. Ciesla DJ, Moore EE, Johnson JL. Decreased progression of postinjury lung dysfunction to the acute respiratory distress syndrome and multiple organ failure. Surgery. 2006;140(4):640-7.

9. Festic E, Kor DJ, Gajic O. Prevention of ARDS. Curr Opin Crit Care. 2015;21(1):8290.

10. Siegel MD. Acute respiratory distress syndrome: Prognosis and outcomes in adults [Internet]. UpToDate. 2019. Available from: https://www.uptodate.com/contents/ acute-respiratory-distress-syndrome-prognosis-and-outcomes-in-adults/

11. Bellani G, Laffey JG, Pham T, Fan E, Brochard L, Esteban A, et al. Epidemiology, Patterns of Care, and Mortality for Patients With Acute Respiratory Distress Syndrome in Intensive Care Units in 50 Countries. JAMA. 2016;315(8):788-800.

12. Gajic $O$, Dabbagh $O$, Park PK, Adesanya A, Chang SY, Hou P, et al. Early identification of patients at risk of acute lung injury: evaluation of lung injury prediction score in a multicenter cohort study. Am J Respir Crit Care Med. 2011;183(4):462-70.

13. Beitler JR, Schoenfeld D, Thompson BT. Preventing ARDS: Progress, Promise, and Pitfalls. Chest. 2014;146(4):1102-13.

14. Agrawal A, Matthay MA, Kangelaris $\mathrm{KN}$, Stein J, Chu JC, Imp BM, et al. Plasma angiopoietin-2 predicts the onset of acute lung injury in critically ill patients. Am J Respir Crit Care Med. 2013;187(7):736-42.

15. Festic E, Bansal V, Kor DJ, Gajic O, US Critical Illness and Injury Trials Group: Lung Injury Prevention Study Investigators (USCIITG-LIPS). SpO2/FiO2 ratio on hospital admission is an indicator of early acute respiratory distress syndrome development among patients at risk. J Intensive Care Med. 2013;30(4):209-16.

16. Zarbock A, Singbartl K, Ley K. Complete reversal of acid-induced acute lung injury by blocking of platelet-neutrophil aggregation. J Clin Invest. 2006;116(12):3211-9.

17. Looney MR, Nguyen JX, Hu Y, Ziffle JA, Lowell CA, Matthay MA. Platelet depletion and aspirin treatment protect mice 
in a two-event model of transfusion-related acute lung injury. J Clin Invest. 2009;119(11):3450-61.

18. Ortiz-Muñoz G, Mallavia B, Bins A, Headley M, Krummel MF, Looney MR. Aspirin-triggered 15-epi-lipoxin A4 regulates neutrophil-platelet aggregation and attenuates acute lung injury in mice. Blood. 2014 Oct;124(17):2625-34. .

19. Melot C, Lejeune P, Naeije R, Leeman M, Hallemans R. Effects of increased pulmonary vascular tone on gas exchange in canine oleic acid pulmonary edema. J Appl Physiol. 2017;65(2):662-8.

20. Kor DJ, Carter RE, Park PK, Festic E, Banner-Goodspeed VM, Hinds R, et al. Effect of Aspirin on Development of ARDS in AtRisk Patients Presenting to the Emergency Department. The LIPS-A Randomized Clinical Trial. JAMA. 2016;315(22):2406-14.

21. Erlich JM, Talmor D, Cartin-Ceba R, Gajic O, Kor DJ. Prehospitalization antiplatelet therapy is associated with a reduced incidence of acute lung injury: a population-based cohort study. Chest. 2011;139(2):289-95.

22. Yadav H, Thompson BT, Gajic O. Fifty Years of $\mathrm{R}$ esearch in ARDS.Is Acute Respiratory Distress Syndrome a Preventable Disease? Am J Respir Crit Care Med. 2017 Mar 15;195(6):725-36.

23. Bone RC, Fisher CJ, Clemmer TP, Slotman GJ, Metz CA. Early methylprednisolone treatment for septic syndrome and the adult respiratory distress syndrome. Chest. 1987 Dec;92(6):1032-6.

24. Luce JM, Montgomery AB, Marks JD, Turner J, Metz CA, Murray JF. Ineffectiveness of High-dose Methylprednisolone in Preventing Parenchymal Lung Injury and Improving Mortality in Patients with Septic Shock. Am Rev Respir Dis. 1988 Jul;138(1):62-8.

25. Pirat $A$, Zeyneloglu $P$, Aldemir D, Yücel $M$, Ozen O, Candan S, et al. Pretreatment with simvastatin reduces lung injury related to intestinal ischemia-reperfusion in rats. Anesth Analg. 2006 Jan 1;102(1):225-32.

26. Yao H-W, Mao L-G, Zhu J-P. PROTECTIVE EFFECTS OF PRAVASTATIN IN MURINE LIPOPOLYSACCHARIDE-INDUCED ACUTE LUNG INJURY. Clin Exp Pharmacol Physiol. 2006 Sep 1;33(9):793-7.

27. O'Neal HR, Koyama T, Koehler EAS, Siew E, Curtis BR, Fremont RD, et al. Prehospital statin and aspirin use and the prevalence of severe sepsis and acute lung injury/acute respiratory distress syndrome*. Crit Care Med. 2011 Jun;39(6):1343-50.

28. Bajwa EK, Malhotra CK, Thompson BT,
Christiani DC, Gong MN. Statin therapy as prevention against development of acute respiratory distress syndrome: an observational study. Crit Care Med. 2012 May;40(5):1470-7.

29. Yadav H, Lingineni RK, Slivinski EJ, Stockler KA, Subramanian A, Oderich GS, et al. Preoperative Statin Administration Does Not Protect Against Early Postoperative Acute Respiratory Distress Syndrome. Anesth Analg. 2014 Oct;119(4):891-8.

30. Xiong B, Wang C, Tan J, Cao Y, Zou Y, Yao $Y$, et al. Statins for the prevention and treatment of acute lung injury and acute respiratory distress syndrome: A systematic review and meta-analysis. Respirology. 2016 Aug 1;21(6):1026-33.

31. Idell S, Kueppers F, Lippmann M, Rosen H, Niederman M, Fein A. Angiotensin converting enzyme in bronchoalveolar lavage in ARDS. Chest. 1987 Jan;91(1):52-6.

32. Marshall RP, Gohlke P, Chambers RC, Howell DC, Bottoms SE, Unger T, et al. Angiotensin II and the fibroproliferative response to acute lung injury. Am J Physiol Cell Mol Physiol. 2004 Jan;286(1):L156-64.

33. Wösten-van Asperen RM, Lutter R, Haitsma JJ, Merkus MP, van Woensel JB, van der Loos CM, et al. ACE mediates ventilator-induced lung injury in rats via angiotensin II but not bradykinin. Eur Respir J. 2008 Feb 1;31(2):363-71.

34. Trillo-Alvarez C, Kashyap R, Kojicic M, Li G, Thakur S, Cartin-Ceba R, et al. Chronic Use of Angiotensin Pathway Inhibitors Is Associated with a Decreased Risk of Acute Respiratory Distress Syndrome. In: C54 ALI/ARDS: DIAGNOSIS AND OUTCOMES. American Thoracic Society; 2009. p. A4638.

35. Watkins TR, Lemos-Filho LB, Dabbagh O, Chang SY, Park PK, Gong MiN. Use Of Angiotensin Converting Enzyme Inhibitors Or Angiotensin Receptor Blockers And Clinical Outcomes Among Patients At-risk For Acute Lung Injury. In: D16 EPIDEMIOLOGY OF ACUTE LUNG INJURY. American Thoracic Society; 2011. p. A5598-A5598.

36. Tagliaferri S, Porri D, De Giuseppe R, Manuelli M, Alessio F, Cena H. The controversial role of vitamin $\mathrm{D}$ as an antioxidant: results from randomised controlled trials. Nutr Res Rev. 2018 Oct;1-7.

37. Thickett DR, Moromizato T, Litonjua AA, Amrein K, Quraishi SA, Lee-Sarwar KA, et al. Association between prehospital vitamin $D$ status and incident acute respiratory failure in critically ill patients: a retrospective 
cohort study. BMJ Open Respir Res. 2015 Jun;2(1):e000074.

38. Dancer RCA, Parekh D, Lax S, D'Souza V, Zheng S, Bassford CR, et al. Vitamin D deficiency contributes directly to the acute respiratory distress syndrome (ARDS). Thorax. $2015 \mathrm{Jul} ; 70(7): 617-24$.

39. Park S, Lee MG, Hong SB, Lim CM, Koh $Y$, Huh JW. Effect of vitamin D deficiency in korean patients with acute respiratory distress syndrome. Korean J Intern Med. 2018;33(6):1129-36.

40. Tanaka K-I, Sugizaki T, Kanda Y, Tamura F, Niino T, Kawahara M. Preventive Effects of Carnosine on Lipopolysaccharide-induced Lung Injury. Sci Rep. 2017 Dec;7(1):42813.

41. Christie JD, Vaslef S, Chang PK, May AK, Gunn SR, Yang S, et al. A Randomized Dose-Escalation Study of the Safety and Anti-Inflammatory Activity of the p38 Mitogen-Activated Protein Kinase Inhibitor Dilmapimod in Severe Trauma Subjects at Risk for Acute Respiratory Distress Syndrome. Crit Care Med. 2015 Sep;43(9):1859-69.

42. Barratt S, Medford AR, Millar AB. Vascular endothelial growth factor in acute lung injury and acute respiratory distress syndrome. Respiration. 2014;87(4):329-42.

43. Jansson A-H, Eriksson C, Wang X. Effects of budesonide and $\mathrm{N}$-acetylcysteine on acute lung hyperinflation, inflammation and injury in rats. Vascul Pharmacol. 2005 Aug;43(2):101-11.

44. Festic E, Carr GE, Cartin-Ceba R, Hinds RF, Banner-Goodspeed V, Bansal V, et al. Randomized Clinical Trial of a Combination of an Inhaled Corticosteroid and Beta Agonist in Patients at Risk of Developing the Acute Respiratory Distress Syndrome. Crit Care Med. 2017 May;45(5):798-805.

45. Young $E$. The anti-inflammatory effects of heparin and related compounds. Thromb Res. 2008 Jan;122(6):743-52.

46. Miller AC, Elamin EM, Suffredini AF. Inhaled Anticoagulation Regimens for the Treatment of Smoke Inhalation-Associated Acute Lung Injury. Crit Care Med. 2014 Feb;42(2):413-9.

47. Slutsky AS. Neuromuscular Blocking Agents in ARDS. N Engl J Med. 2010 Sep;363(12):1176-80.

48. He T, Tao J, Wang X, Wang X. Effects of cisatracurium in combination with ventilation on inflammatory factors and immune variations in sepsis rats. Exp Ther Med. 2018 Mar;15(5):4414-8.

49. Sottile PD, Albers D, Moss MM. Neuromuscular blockade is associated with the attenuation of biomarkers of epithelial and endothelial injury in patients with moderate-to-severe acute respiratory distress syndrome. Crit Care. 2018 Dec;22(1):63.

50. Ianaro $A$, lalenti $A$, Maffia $P$, Sautebin $L$, Rombolà L, Carnuccio R, et al. Anti-inflammatory activity of macrolide antibiotics. J Pharmacol Exp Ther. 2000;292(1):156-63.

51. Tamaoki J, Kondo M, Kohri K, Aoshiba K, Tagaya E, Nagai A. Macrolide antibiotics protect against immune complex-induced lung injury in rats: role of nitric oxide from alveolar macrophages. J Immunol (Baltimore, Md 1950). 1999;163(5):2909-15.

52. Cramer CL, Patterson A, Alchakaki A, Soubani AO. Immunomodulatory indications of azithromycin in respiratory disease: a concise review for the clinician. Postgrad Med. 2017;129(5):493-9.

53. Hara K, Shirai R, Sakito O, Abe K, Kohno $S$, Kadota J. Interleukin $1 \beta$, Tumor Necrosis Factor Alpha, and Interleukin 8 in Bronchoalveolar Lavage Fluid of Patients with Diffuse Panbronchiolitis: A Potential Mechanism of Macrolide Therapy. Respiration. 2009;63(1):42-8.

54. Walkey AJ, Wiener RS. Macrolide antibiotics and survival in patients with acute lung injury. Chest. 2012;141(5):1153-9.

55. Kawamura K, Ichikado K, Takaki M, Sakata $Y$, Yasuda Y, Shingu N, et al. Efficacy of azithromycin in sepsis-associated acute respiratory distress syndrome: a retrospective study and propensity score analysis. Springerplus. 2016;5(1):1-7.

56. Bos LD, Simonis FD, van der Poll T, Ong DSY, de ludicibus G, Cremer OL, et al. Macrolide therapy is associated with reduced mortality in acute respiratory distress syndrome (ARDS) patients. Ann Transl Med. 2018;6(2):24-24.

57. Cakarova L, Marsh LM, Wilhelm J, Mayer $\mathrm{K}$, Grimminger F, Seeger W, et al. Macrophage tumor necrosis factor- $\alpha$ induces epithelial expression of granulocyte-macrophage colony-stimulating factor: Impact on alveolar epithelial repair. Am J Respir Crit Care Med. 2009;180(6):521-32.

58. Rösler B, Herold S. Lung epithelial GMCSF improves host defense function and epithelial repair in influenza virus pneumonia-a new therapeutic strategy? Mol Cell Pediatr. 2016;3(1).

59. Ballinger MN, Paine $\mathrm{R}$, Serezani $\mathrm{CHC}$, Aronoff DM, Choi ES, Standiford TJ, et al. Role of granulocyte macrophage colony-stimulating factor during gram-negative lung infection with Pseudomonas 
aeruginosa. Am J Respir Cell Mol Biol. 2006;34(6):766-74.

60. Paine R, Standiford TJ, Dechert RE, Moss M, Martin GS, Rosenberg AL, et al. A randomized trial of recombinant human granulocyte-macrophage colony stimulating factor for patients with acute lung injury*. Crit Care Med. 2012 Jan;40(1):90-7.

61. Zhang M, Jativa DF. Vitamin C supplementation in the critically ill: A systematic review and meta-analysis. SAGE open Med. 2018;6:2050312118807615.

62. Bharara A, Grossman C, Grinnan D, Syed A, Fisher B, DeWilde C, et al. Intravenous Vitamin C Administered as Adjunctive Therapy for Recurrent Acute Respiratory Distress Syndrome. Case Reports Crit Care. 2016;2016:1-4.

63. Res Respir Med Open PJ, Kim C, Debesa $\mathrm{O}$, Nicolato $\mathrm{P}$, Fisher B, Natarajan $\mathrm{R}$, et al. PULMONARY RESEARCH AND RESPIRATORY MEDICINE Vitamin C Infusion for Gastric Acid Aspiration-Induced Acute Respiratory Distress Syndrome (ARDS) Article History Citation. J. 2017;4(2):33-7.

64. Fowler III AA, Kim C, Lepler L, Malhotra R, Debesa $O$, Natarajan $R$, et al. Intravenous vitamin $\mathrm{C}$ as adjunctive therapy for enterovirus/rhinovirus induced acute respiratory distress syndrome. World J Crit Care Med. 2017 Feb 4;6(1):85.

65. Jain M, Chandel NS. Rethinking Antioxidants in the Intensive Care Unit. Am J Respir Crit Care Med. 2013 Dec 1;188(11):12835.

66. Mitsopoulos P, Omri A, Alipour M, VermeuIen N, Smith MG, Suntres ZE. Effectiveness of liposomal-N-acetylcysteine against LPS-induced lung injuries in rodents. Int $\mathrm{J}$ Pharm. 2008 Nov;363(1-2):106-11.

67. Chen C, Guan X, Quinn DA, Ouyang B. $\mathrm{N}$-Acetylcysteine Inhibits Ventilation-Induced Collagen Accumulation in the Rat Lung. Tohoku J Exp Med. 2015;236(4):255-61.

68. Adhikari NK, Burns KE, Meade MO, Ratnapalan M. Pharmacologic therapies for adults with acute lung injury and acute respiratory distress syndrome. Cochrane Database Syst Rev. 2004 Oct 18;(4):CD004477.

69. Szakmany T, Hauser B, Radermacher P. $\mathrm{N}$-acetylcysteine for sepsis and systemic inflammatory response in adults. Cochrane Database Syst Rev. 2012 Sep 12;(9):CD006616.

70. Zhang Y, Ding S, Li C, Wang Y, Chen Z, Wang $\mathrm{Z}$. Effects of $\mathrm{N}$-acetylcysteine treatment in acute respiratory distress syndrome: A meta-analysis. Exp Ther Med.
2017 Oct;14(4):2863-8.

71. Heyland D, Muscedere J, Wischmeyer PE, Cook D, Jones G, Albert M, et al. A Randomized Trial of Glutamine and Antioxidants in Critically III Patients. N Engl J Med. 2013 Apr 18;368(16):1489-97.

72. Oliveira GP, de Abreu MG, Pelosi P, Rocco PRM. Exogenous Glutamine in Respiratory Diseases: Myth or Reality? Nutrients. 2016 Feb 4;8(2):76.

73. Traber MG, Atkinson J. Vitamin E, antioxidant and nothing more. Free Radic Biol Med. 2007 Jul 1;43(1):4-15.

74. Nathens $A B$, Neff MJ, Jurkovich GJ, Klotz P, Farver K, Ruzinski JT, et al. Randomized, prospective trial of antioxidant supplementation in critically ill surgical patients. Ann Surg. 2002 Dec;236(6):814-22.

75. Crimi E, Liguori A, Condorelli M, Cioffi M, Astuto M, Bontempo P, et al. The Beneficial Effects of Antioxidant Supplementation in Enteral Feeding in Critically III Patients: A Prospective, Randomized, Double-Blind, Placebo-Controlled Trial. Anesth Analg. 2004 Sep;99(3):857-63.

76. Kawata A, Murakami Y, Suzuki S, Fujisawa S. Anti-inflammatory Activity of $\beta$-Carotene, Lycopene and Tri-n-butylborane, a Scavenger of Reactive Oxygen Species. In Vivo. 2018;32(2):255-64.

77. Rice TW, Wheeler AP, Thompson BT, deBoisblanc BP, Steingrub J, Rock P, et al. Enteral omega-3 fatty acid, gamma-linolenic acid, and antioxidant supplementation in acute lung injury. JAMA. 2011 Oct 12;306(14):1574-81.

78. Calder PC. n-3 Fatty acids, inflammation, and immunity - Relevance to postsurgical and critically III patients. Lipids. 2004 Dec 1;39(12):1147-61.

79. Singer $P$, Theilla M, Fisher $H$, Gibstein L, Grozovski E, Cohen J. Benefit of an enteral diet enriched with eicosapentaenoic acid and gamma-linolenic acid in ventilated patients with acute lung injury. Crit Care Med. 2006 Apr 1;34(4):1033-8.

80. Chen M, Lu J, Chen Q, Cheng L, Geng Y, Jiang $H$, et al. [Statin in the treatment of ALI/ARDS: a systematic review and Meta-analysis based on international databases]. Zhonghua Wei Zhong Bing Ji Jiu Yi Xue. 2017;29(1):51-6. .

81. Nagendran M, McAuley DF, Kruger PS, Papazian L, Truwit JD, Laffey JG, et al. Statin therapy for acute respiratory distress syndrome: an individual patient data meta-analysis of randomised clinical trials. Intensive Care Med. 2017 May 21;43(5):663-71. 
82. Feng Y. Efficacy of statin therapy in patients with acute respiratory distress syndrome/ acute lung injury: a systematic review and meta-analysis. Eur Rev Med Pharmacol Sci. 2018 May;22(10):3190-8.

83. Davidson WJ, Dorscheid D, Spragg R, Schulzer M, Mak E, Ayas NT. Exogenous pulmonary surfactant for the treatment of adult patients with acute respiratory distress syndrome: results of a meta-analysis. Crit Care. 2006;10(2):R41.

84. Meng S-S, Chang W, Lu Z-H, Xie J-F, Qiu $\mathrm{H}-\mathrm{B}$, Yang $\mathrm{Y}$, et al. Effect of surfactant administration on outcomes of adult patients in acute respiratory distress syndrome: a meta-analysis of randomized controlled trials. BMC Pulm Med. 2019 Dec 9;19(1):9.

85. Ware LB, Matthay MA. Keratinocyte and hepatocyte growth factors in the lung: roles in lung development, inflammation, and repair. Am J Physiol Cell Mol Physiol. 2002 May;282(5):L924-40.

86. Shyamsundar M, McAuley DF, Ingram RJ, Gibson DS, O'Kane D, McKeown ST, et al. Keratinocyte Growth Factor Promotes Epithelial Survival and Resolution in a Human Model of Lung Injury. Am J Respir Crit Care Med. 2014 Jun 15;189(12):1520-9.

87. HASHIMOTO S, OKAYAMA $Y$, SHIME N, KIMURAA, FUNAKOSHI Y, KAWABATA K, et al. Neutrophil elastase activity in acute lung injury and respiratory distress syndrome. Respirology. 2008 Jun;13(4):5814.

88. Zeiher BG, Artigas A, Vincent J-L, Dmitrienko A, Jackson K, Thompson BT, et al. Neutrophil elastase inhibition in acute lung injury: results of the STRIVE study. Crit Care Med. 2004 Aug;32(8):1695-702.

89. Iwata K, Doi A, Ohji G, Oka H, Oba Y, Takimoto K, et al. Effect of neutrophil elastase inhibitor (sivelestat sodium) in the treatment of acute lung injury (ALI) and acute respiratory distress syndrome (ARDS): a systematic review and meta-analysis. Intern Med. 2010;49(22):2423-32.

90. Mutlu GM, Dumasius V, Burhop J, McShane PJ, Meng FJ, Welch L, et al. Upregulation of Alveolar Epithelial Active $\mathrm{Na}+$ Transport Is Dependent on $\beta 2$-Adrenergic Receptor Signaling. Circ Res. 2004 Apr 30;94(8):1091-100.

91. Sartori C, Allemann $Y$, Duplain H, Lepori M, Egli M, Lipp E, et al. Salmeterol for the Prevention of High-Altitude Pulmonary Edema. N Engl J Med. 2002 May 23;346(21):1631-6.

92. National Heart, Lung, and Blood Institute Acute Respiratory Distress Syndrome
(ARDS) Clinical Trials Network TN, Matthay MA, Brower RG, Carson S, Douglas IS, Eisner $M$, et al. Randomized, placebo-controlled clinical trial of an aerosolized $\beta_{2}$-agonist for treatment of acute lung injury. Am J Respir Crit Care Med. 2011 Sep 1;184(5):561-8.

93. Gao Smith F, Perkins GD, Gates S, Young D, McAuley DF, Tunnicliffe W, et al. Effect of intravenous $\beta$-2 agonist treatment on clinical outcomes in acute respiratory distress syndrome (BALTI-2): a multicentre, randomised controlled trial. Lancet (London, England). 2012 Jan 21;379(9812):229-35.

94. Abraham E, Park YC, Covington P, Conrad SA, Schwartz M. Liposomal prostaglandin $\mathrm{E} 1$ in acute respiratory distress syndrome: a placebo-controlled, randomized, double-blind, multicenter clinical trial. Crit Care Med. 1996 Jan;24(1):10-5.

95. Abraham E, Baughman R, Fletcher E, Heard S, Lamberti J, Levy $\mathrm{H}$, et al. Liposomal prostaglandin E1 (TLC C-53) in acute respiratory distress syndrome: a controlled, randomized, double-blind, multicenter clinical trial. TLC C-53 ARDS Study Group. Crit Care Med. 1999 Aug;27(8):1478-85.

96. Fuller BM, Mohr NM, Skrupky L, Fowler S, Kollef $\mathrm{MH}$, Carpenter CR. The use of inhaled prostaglandins in patients with ARDS: a systematic review and meta-analysis. Chest. 2015 Jun;147(6):1510-22.

97. Rossaint R, Falke KJ, Lopez F, Slama K, Pison U, Zapol WM. Inhaled Nitric Oxide for the Adult Respiratory Distress Syndrome. N Engl J Med. 1993 Feb 11;328(6):399-405.

98. Gebistorf F, Karam O, Wetterslev J, Afshari A. Inhaled nitric oxide for acute respiratory distress syndrome (ARDS) in children and adults. Cochrane Database Syst Rev. 2016 Jun 27;(6).

99. Welty-Wolf KE, Carraway MS, Ortel TL, Piantadosi CA. Coagulation and inflammation in acute lung injury. Thromb Haemost. 2002 Jul;88(1):17-25.

100.Ware LB, Matthay MA, Parsons PE, Thompson BT, Januzzi JL, Eisner MD, et al. Pathogenetic and prognostic significance of altered coagulation and fibrinolysis in acute lung injury/acute respiratory distress syndrome. Crit Care Med. 2007 Aug;35(8):1821-8.

101. Cornet AD, Groeneveld ABJ, Hofstra JJ, Vlaar AP, Tuinman PR, van Lingen A, et al. Recombinant human activated protein $C$ in the treatment of acute respiratory distress syndrome: a randomized clinical trial. PLoS One. 2014;9(3):e90983. 